\title{
Trophic mismatch requires seasonal heterogeneity of warming
}

\author{
Dietmar Straile, ${ }^{1,3}$ Onur Kerimoglu, ${ }^{1,2}$ and Frank Peeters ${ }^{1}$ \\ ${ }^{1}$ Limnological Institute, Department of Biology, University of Konstanz, 78464 Konstanz, Germany \\ ${ }^{2}$ Institute of Coastal Research, Helmholtz-Zentrum Geesthacht, 21502 Geesthacht, Germany
}

\begin{abstract}
Climate warming has been shown to advance the phenology of species. Asynchronous changes in phenology between interacting species may disrupt feeding interactions (phenological mismatch), which could have tremendous consequences for ecosystem functioning. Long-term field observations have suggested asynchronous shifts in phenology with warming, whereas experimental studies have not been conclusive. Using proxy-based modeling of three trophic levels (algae, herbivores, and fish), we show that asynchronous changes in phenology only occur if warming is seasonally heterogeneous, but not if warming is constant throughout the year. If warming is seasonally heterogeneous, the degree and even direction of asynchrony depends on the specific seasonality of the warming. Conclusions about phenological mismatches in food web interactions may therefore produce controversial results if the analyses do not distinguish between seasonally constant and seasonal specific warming. Furthermore, our results suggest that predicting asynchrony between interacting species requires reliable warming predictions that resolve sub-seasonal time scales.
\end{abstract}

Key words: climate warming; Daphnia; fish; food webs; Lake Constance, Germany; mismatch; phenology; plankton; whitefish.

\section{INTRODUCTION}

Plant and animal populations have been shown to respond to global warming via changes in their phenology (Parmesan and Yohe 2003, Thackeray et al. 2010, Ovaskainen et al. 2013, Poloczanska et al. 2013). A key concern for ecosystem functioning is that these responses differ between interacting species, resulting in changing time spans between phenological events (Visser and Both 2005, Thackeray et al. 2010, Blois et al. 2013). This, in turn, may result in the disruption of evolved feeding interactions (Visser and Both 2005, Blois et al. 2013), i.e., temporal separation of the supply of lower trophic levels from the demand of higher ones ("match-mismatch hypothesis"; Cushing 1990). Such food web disruptions and changes in population fitness due to phenological change have indeed been reported in terrestrial, marine, and freshwater food webs (Winder and Schindler 2004, Visser and Both 2005, Both et al. 2009).

The term "mismatch" in Cushing's (1990) hypothesis suggests negative consequences for the consumer. However, in the literature, mismatch has often been defined in a much broader sense: as between-species heterogeneity in phenological advancement, e.g., heterogeneity between producers and consumers regardless of the consequences for consumers. In the following, we use the term "mismatch" in this broad sense.

Manuscript received 6 May 2014; revised 3 April 2015; accepted 8 April 2015. Corresponding Editor: J. C. Trexler.

${ }^{3}$ E-mail: dietmar.straile@uni-konstanz.de
During the last few decades, mismatches have been widely reported for species in all major ecosystems of the world, including terrestrial, marine, and freshwater systems (Parmesan and Yohe 2003, Thackeray et al. 2010, Poloczanska et al. 2013), whereas studies on the consequences of mismatches for consumers have been much less numerous (but see, e.g., Winder and Schindler 2004, Visser and Both 2005, Both et al. 2009). In contrast to the ubiquity of mismatches (but see Adrian et al. 2006, Seebens et al. 2009) in studies analyzing longterm data series, experimental work has provided weak or inconclusive support for mismatches even in the broad sense of the term (Nicolle et al. 2012, Sommer et al. 2012, Stewart et al. 2013, Berger et al. 2014). This discrepancy is especially striking as the difference between warming and current temperature conditions usually employed in experiments, e.g., $2-6^{\circ} \mathrm{C}$ (Sommer et al. 2012, Stewart et al. 2013) strongly exceeds the degree of global warming observed during the last decades (IPCC 2013).

Here we used hydrodynamic modeling of temperature proxies to analyze the extent to which seasonal heterogeneity in warming may resolve the discrepancy between the observational and experimental evidence for mismatches. Using different warming scenarios, we predicted phenological advancement and its heterogeneity between three trophic levels (see Plate 1) with seasonally constant and seasonally heterogeneous warming. We focused on phenological events in a deep stratifying freshwater ecosystem, i.e., the onset of the primary producers' vegetation period (onset of the vernal algal bloom, $\mathrm{OAB}$ ), the timing of the herbivores' 
maximum density (timing of maximum Daphnia abundances, TMD), and the timing of the predators' reproduction and offspring emergence (timing of whitefish Coregonus lavaretus L. spawning, TWS, and egg hatching, TWH). Various studies have shown that these phenologies have been changing with global warming (Winder and Schindler 2004, Adrian et al. 2006, George 2012, Straile et al. 2012, Warren et al. 2012). Furthermore, there is evidence that phenological advancement may differ between trophic levels with presumably negative consequences for Daphnia population development (Winder and Schindler 2004, George 2012). Likewise, fish growth and survival may depend on the match-mismatch of whitefish hatching with the onset of the phytoplankton bloom and the timing of the Daphnia maximum (Ohlberger et al. 2014). Whitefish larvae feed during their first weeks on small plankton such as ciliates, rotifers, and copepod nauplii, the abundance of which increases with the onset of the spring phytoplankton bloom, whereas juveniles strongly depend on Daphnia for growth and survival.

As several presumably opposing processes are involved in these phenologies, it is unclear whether mismatching should be expected to occur between trophic levels. For example, whitefish hatching will depend on the timing of spawning and the egg developmental time. As warming is expected to delay fall spawning, but decrease developmental time, it is unclear whether whitefish hatching will change at a similar rate, as, e.g., the onset of the algal bloom that shifts forward in response to altered mixing conditions in spring (Peeters et al. 2007b).

In a warmer climate, water temperatures at the onset of the algal bloom are predicted to be higher than in the current climate (Peeters et al. 2007a). As the timing of the Daphnia maximum occurs at a fixed water isotherm (Straile et al. 2012), the time span between the onset of the algal bloom and the Daphnia maximum may be shorter than in the current climate if the overall heat flux at the lake's surface remains unchanged. However, as the onset of the algal bloom advances in a warmer world, solar radiation at the bloom's onset will be lower, and thus warming of the surface waters will be reduced. Whether a mismatch between the timing of algal onset and the Daphnia maximum will occur with climate warming may depend on the relative importance between year-round warming determining the temperature at algal bloom onset and seasonal warming determining the seasonal advance of the algal bloom.

Temperature-related proxies for the phenological events of all three trophic levels have been established for our study system, Lake Constance (see Material and Methods). These proxies are likely to be applicable beyond this specific ecosystem because the onset of the algal bloom depends on the onset of stratification in all deep water bodies (Huisman et al. 1999, Peeters et al. 2007b), the timing of the spring Daphnia maximum is closely associated with water temperature in lakes across the Northern Hemisphere (Straile et al. 2012), and later fall spawning with higher temperatures is typically observed for salmonids (Heggberget 1988, Pankhurst and Munday 2011, Warren et al. 2012). As phenologies are expected to track the changes in seasonal temperature distribution with warming (Burrows et al. 2011), hydrodynamic modeling of the impact of warming on seasonal isotherm changes allows the change in phenology, and thus also the time spans between phenological events to be predicted in a warmer climate without the need to fit a complex biological-hydrodynamic model to a specific system.

\section{Materials And Methods \\ Description of phenological proxies}

The phenological events analyzed in this study have been shown to be tightly linked to the seasonal temperature development in the water column. In deep lakes such as Lake Constance, phytoplankton growth during winter is severely light limited, and the onset of the bloom depends on the onset of stratification. Using a simulation model, Peeters et al. (2007b) have shown that the onset of the algal bloom (OAB) in Lake Constance can be reliably predicted as time (day of the year, doy, defined as days since 1 January) when the difference in water temperature between the surface $\left(T_{\text {surface }}\right)$ and 40 m depth $\left(T_{40 \mathrm{~m}}\right)$ exceeds $1{ }^{\circ} \mathrm{C}$ (measured as doy):

$$
\mathrm{OAB}=\operatorname{Timing}\left(\left(T_{\text {surface }}-T_{40 \mathrm{~m}}\right)>1{ }^{\circ} \mathrm{C}\right) .
$$

The timing of the Daphnia maximum (TDM, measured as doy) is tightly connected to the vernal increase of water temperature. Straile et al. (2012) have shown that across the Northern Hemisphere, i.e., from Mediterranean to Arctic lakes, the timing of the Daphnia maximum is a linear function of the $13^{\circ} \mathrm{C}$ isotherm in the upper $5 \mathrm{~m}$ of the water column (measured as doy):

$$
\mathrm{TDM}=22.25+0.99 \times \text { Timing } 13^{\circ} \mathrm{C} \text { isotherm } .
$$

The timing of whitefish hatching (TWH, measured as doy) can be predicted given knowledge of the timing of whitefish spawning (TWS; measured as doy) and the duration of egg development (measured in days; Heggberget 1988):

$$
\text { TWH }=\text { TWS }+ \text { Developmental time. }
$$

The egg developmental time of fish (measured in days) is tightly connected to the environmental temperature. Developmental time as a response to temperature for the Lake Constance whitefish ("Blaufelchen") Coregonus lavaretus L. has been studied experimentally (Eckmann 1987) and shown to be well predicted from ambient temperatures $\left(T\right.$; measured in $\left.{ }^{\circ} \mathrm{C}\right)$ :

$$
\text { Developmental time }=138.099-47.996 \times \ln (T) .
$$

As the Lake Constance whitefish is an open water spawner and its eggs sink down to a depth of 200 to 250 m (Straile et al. 2007), we used the average temperature 
within the $200-250 \mathrm{~m}$ depth interval to calculate developmental time.

Whitefish spawning phenology in Lake Constance has been shown to be a linear function of the mean November water temperature at a depth of $10 \mathrm{~m}$ (Wahl and Löffler 2009). However, predictions of phenology with warming based on the mean temperature of a specific period are likely to be erroneous because it is unclear if, in a warmer world with altered phenology, the chosen time period will still be relevant for this phenological event. Furthermore, organisms may respond to changes in seasonal temperatures, i.e., seasonal temperature isotherms, rather than to changes in temperature means (Schaper et al. 2012). We therefore used Wahl and Löffler's (2009) data set (whitefish phenology and daily interpolated water temperatures at $10 \mathrm{~m}$ water depth) to develop a relationship between spawning phenology and a seasonal isotherm (Appendix A). Following Wahl and Löffler (2009), we only used the time period from 1988 to 2006 for proxy establishment to remove potential effects of whitefish age structure on spawning phenology. Age structure is influenced by eutrophication because faster growth of fishes results in different age classes that are caught by size-selective fisheries. For the period 1988-2006, no influence of age structure on spawning time was detected (Wahl and Löffler 2009). In an exploratory data analysis, we searched for the best linear relationship between falling below various isotherms in fall and spawning phenology using linear models with autocorrelated errors. Model performance was evaluated using Akaike's information criterion (Appendix A: Fig. Ala). Based on this analysis, we used the $10^{\circ} \mathrm{C}$ isotherm as a predictor of whitefish spawning (Appendix A: Fig. Alb). The $10^{\circ} \mathrm{C}$ isotherm is related to the timing of TWS (measured as doy) by:

$$
\text { TWS }=259+0.26 \times \text { Timing } 10^{\circ} \mathrm{C} \text { isotherm. }
$$

We tested whether there was a significant advance of OAB, TDM, or TWH during the 1979-2007 period and whether these proxies were related to annual mean air temperature and/or the air temperatures of specific months using linear models with autocorrelated errors.

\section{Hydrodynamic modeling}

In large water bodies, air temperature only partially determines the water temperature dynamics due to the influence of other meteorological factors e.g., wind speed and direction and cloud cover. Furthermore, water temperature will not respond immediately to air temperature change due to the thermal structure within the water body and the high heat capacity of water. A specific air temperature increase may have very different effects on water temperature dynamics depending on those other meteorological conditions and the memory of meteorological history in the form of existing thermal structure. To cover a wide range of meteorological conditions, we investigated the effects of warming by simulating water temperature dynamics continuously across a 29-year period, i.e., from 1979 to 2007, instead of focusing on a specific year.

The model utilized in this study is based on the hydrodynamic model SIMSTRAT (Goudsmit et al. 2002), which has been successfully applied in Lake Constance (Peeters et al. 2007b) and in several other deep lakes (e.g., Perroud et al. 2009). The model calculates the development of the vertical temperature distribution from empirical relations for the heat fluxes at the lake surface (Goudsmit et al. 2002) and the vertical transport of heat by vertical turbulent diffusion. Turbulent diffusivities are determined using a $k$ - $\varepsilon$ model (where $k$ is the turbulent kinetic energy, and $\varepsilon$ is the dissipation of turbulent kinetic energy) in combination with a seiche module that channels additional kinetic energy to turbulent kinetic energy during the stratified period.

The model is driven by hourly data on wind speed, wind direction, solar radiation, air temperature, humidity, and cloud cover measured from 1979 to 2007 at the Deutscher Wetterdienst (DWD [German National Meteorological Service]) station in Konstanz. As phenological advancement is expected to alter heat flux across the water surface, a mechanistic understanding of mismatching with warming requires an analysis of heat flux changes. Based on empirical heat flux equations (for details see Appendix B), simulated surface temperatures and meteorological data, we calculated average heat fluxes across the water's surface and average warming rates for the time period between $\mathrm{OAB}$ and TDM in the different warming scenarios.

Details on the preparation of the meteorological data, estimation of seasonally varying light extinction coefficients and model operation are given elsewhere (Peeters et al. 2007b). We used here numerical time steps of one minute. Model validation was performed using a continuous run of the hydrodynamic model from 1979 to 2007. The predicted proxies were compared with observed proxies using major axis regression. All statistical models and graphics were run with the software package R (version 2.9; R Development Core Team 2009) using the packages smatr (Warton et al. 2012) and beanplot (Kampstra 2008).

Temperature data were recorded either continuously with thermistor chains or in years without continuous recordings weekly with a temperature probe during sampling campaigns. When only weekly resolution was available, we interpolated linearly between sampling dates, and proxies were calculated from the interpolated data. For calculation of the observed and predicted proxies, we always used the first date when a specific isotherm was crossed.

The transition from model initialization with temperatures measured in 1979 to conditions that are representative of a warmer climate potentially introduces a bias into the assessment of consequences of a warmer climate for temperature distributions because the high heat capacity of water and the large volume of 

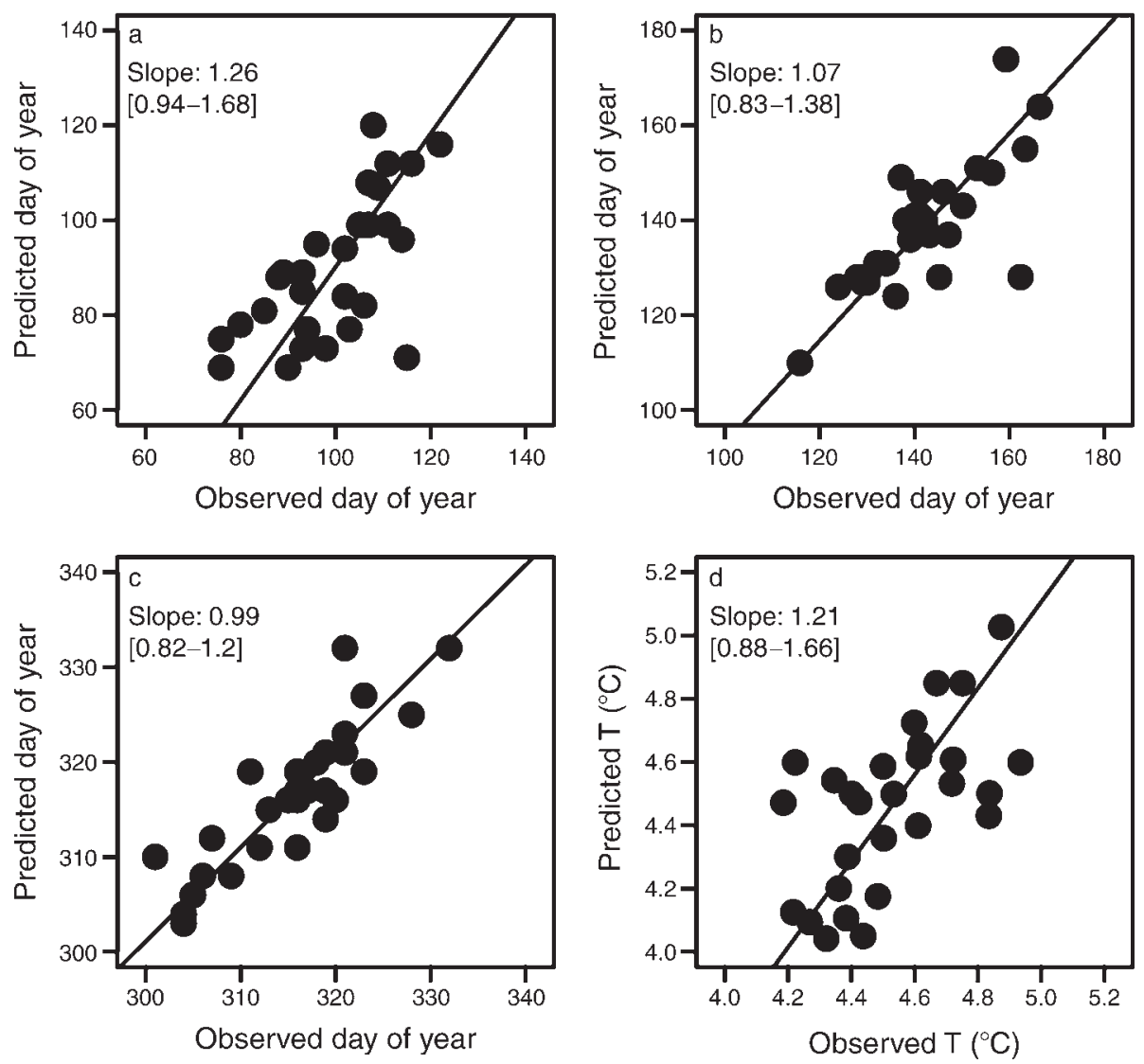

FIG. 1. Comparison of predicted vs. observed phenology proxies and water temperatures during the reference period 1979 2007: (a) the timing (day of year, doy; defined as days since 1 January) when water temperatures during the build-up of stratification between the surface and $40 \mathrm{~m}$ depth first differ by more than $1{ }^{\circ} \mathrm{C}$, (b) the timing (doy) when upper water column temperatures $\left(0-5 \mathrm{~m}\right.$ depth) surpass $13^{\circ} \mathrm{C}$, (c) the timing (doy) when water temperatures at the end of the stratified period fall below the $10^{\circ} \mathrm{C}$ isotherm at a depth of $10 \mathrm{~m}$, and (d) mean deep-water $(200-250 \mathrm{~m})$ temperature $(T)$ during winter (December-January). Lines shown are the results from a major axis (MA) regression. Slopes and confidence intervals (in square brackets) of each MA regression are shown in each panel. MA regressions have the following intercepts and confidence intervals: (a) -35.5 [-72.6 to 1.6], (b) -13.4 [ -52.1 to 25.2$]$, (c) 3.7 [ -65 to 73$]$, and (d) -1.0 [ -2.8 to 0.8$]$.

water in a deep aquatic system result in a slow response of the water's temperature to warming. Therefore, we introduced a 20 -year simulation period as initialization period before simulating the 29 -year time period that serves as the basis for the analysis of the consequences of climate change into all scenario calculations, including that of the reference scenario. During the 20-year initialization period, the model was driven by the meteorological conditions and the light extinction coefficients of the first 10 years of the scenario repeated twice.

The scenarios of climate warming were generated by altering the air temperature in the meteorological time series. We considered seasonally constant warming scenarios that assume a time constant shift in air temperature up to $+4^{\circ} \mathrm{C}$ in steps of $1^{\circ} \mathrm{C}$. Additionally, we considered season-specific warming scenarios that assume a shift in air temperature by $+4^{\circ} \mathrm{C}$ in a specific 28-day period while maintaining a $+2^{\circ} \mathrm{C}$ annual average. We considered 24 different heterogeneous warming scenarios starting either at the 1st or 15th day of each month. These heterogeneous warming scenarios are motivated by the results of global circulation models linked to regional models that predict an overall increase in temperature and high intra-annual variability in warming rates at seasonal and sub-seasonal scales (Räisänen et al. 2004). According to that study, the differences between winter and summer air temperature increases might be as large as $6^{\circ} \mathrm{C}$. Furthermore, warming rates during recent decades have shown striking differences even between adjacent months (e.g., Rebetez and Reinhard 2007, Burakowski et al. 2008).

\section{RESUlts}

A continuous run of the hydrodynamical model during the reference period (1979-2007) yielded very good agreement between predicted and observed phenological proxies (Fig. 1). The model successfully predicts interannual variability of (1) the proxy for the 

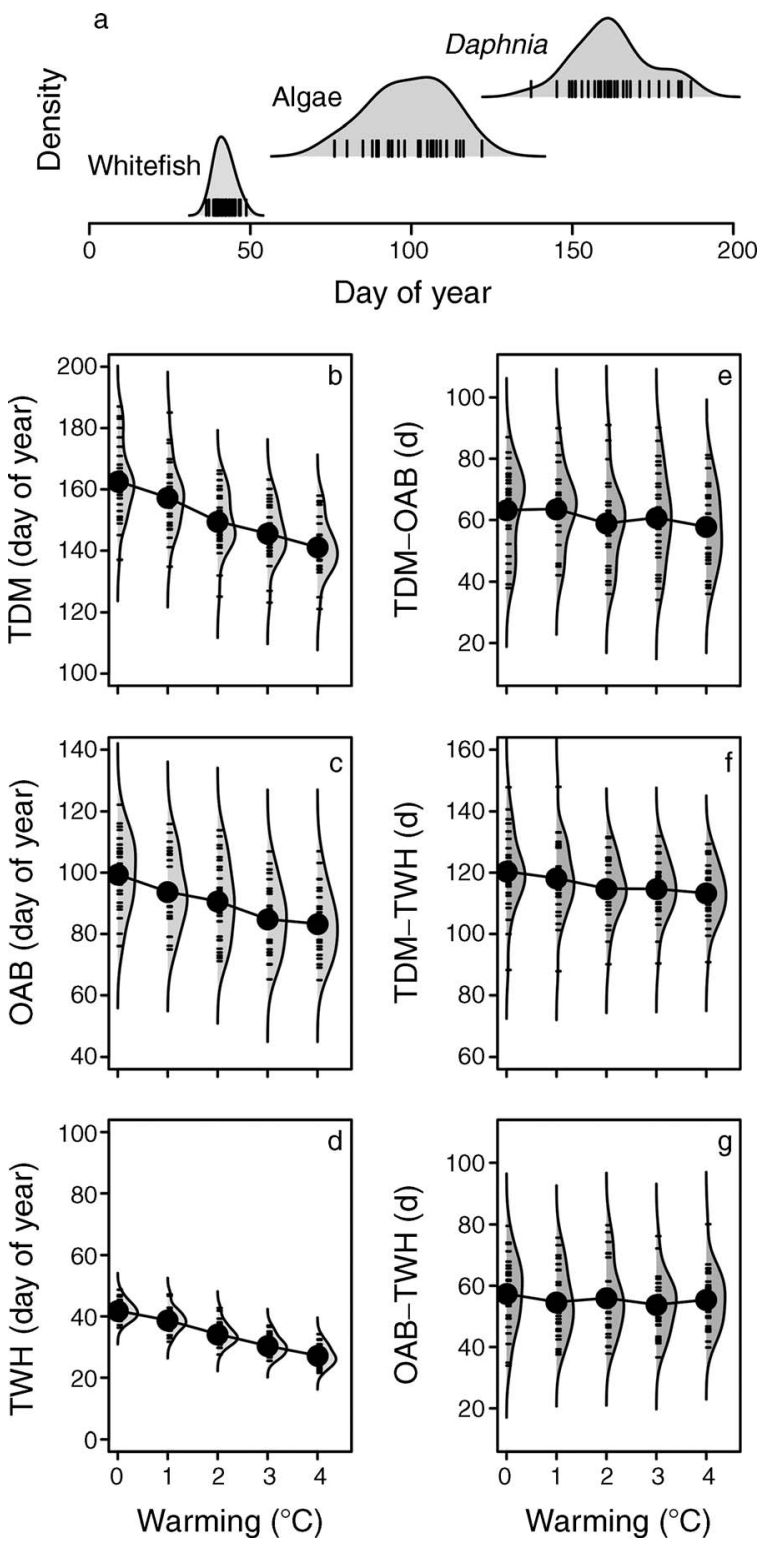

FIG. 2. Density distribution plots (shaded areas) of the phenologies and of time spans between phenologies under reference conditions and seasonally constant warming scenarios. Phenology of $(\mathrm{a}, \mathrm{b})$ the timing of Daphnia maximum (TDM), $(\mathrm{a}, \mathrm{c})$ the onset of the algae bloom $(\mathrm{OAB})$, and $(\mathrm{a}, \mathrm{d})$ the timing of whitefish Coregonus lavaretus L. hatching (TWH), and of the phenological time spans between (e) TDM and OAB, (f) TDM and TWH, and (g) OAB and TWH during (a) 19792007 and $(\mathrm{b}-\mathrm{g})$ under seasonally constant warming scenarios. Black lines connect the means (black dots) of each distribution. Rugs (short black ticks) indicate individual data points.

onset of algal growth, i.e., the timing when the temperature difference between surface and $40 \mathrm{~m}$ depth exceeds $1^{\circ} \mathrm{C}$ (Fig. 1a); (2) the proxy for the timing of the Daphnia maximum, i.e., the timing when upper water layer temperature first exceeds $13^{\circ} \mathrm{C}$ (Fig. 1b); and (3) the proxy for the timing of whitefish hatching requiring two properties of the temperature distribution: The time when the water temperature at the end of the stratified period first falls below $10^{\circ} \mathrm{C}$ at $10 \mathrm{~m}$ depth (Fig. 1c) and deep-water temperatures during winter (Fig. 1d). Furthermore, major axis regression showed that the slopes of the relationships between the predicted and observed proxies did not differ significantly from 1 , and the intercepts of the relationships did not differ significantly from zero (all $P>0.05$ ). Hence, the model provides adequate and unbiased predictions of water temperature dynamics, and consequently, of the proxies needed for phenological predictions.

The proxy calculations indicate that from 1979 to 2007, TWH (mean day of the year, doy: 42) was, on average, 57 days before OAB (mean doy: 99), which was, in turn, 63 days before TDM (mean doy: 163) (Fig. 2a). The phenological variability during this time period was low for TWH (range: 12 days) and high for OAB (range: 46 days) and TDM (range: 50 days). From 1979 to 2007 , the proxy for $\mathrm{OAB}$ advanced by $0.93 \pm 0.37 \mathrm{~d} / \mathrm{yr}$ (means $\pm \mathrm{SE})(t=-2.5, P<0.02)$, that for TDM advanced by $0.87 \pm 0.26 \mathrm{~d} / \mathrm{yr}$, but there was no significant change in the case of TWH $(-0.01 \pm 0.14 \mathrm{~d} / \mathrm{yr}, t=-0.1, P=0.9)$.

The annual mean air temperatures increased during the 1979-2007 period at a rate of $0.06^{\circ} \pm 0.01^{\circ} \mathrm{C} / \mathrm{yr}(t=$ 4.4, $P<0.001)$. However, although the phenological proxy for TDM was significantly related to annual mean air temperatures (slope: $-13.0 \pm 2.9 \mathrm{~d} /{ }^{\circ} \mathrm{C}, t=-4.6, P<$ 0.001 ), those for OAB (slope: $-5.9 \pm 4.2 \mathrm{~d} /{ }^{\circ} \mathrm{C}, t=-1.4$, $P=0.17$ ) and TWH (slope: $-0.8 \pm 1.0 \mathrm{~d} /{ }^{\circ} \mathrm{C}, t=-0.9, P$ $=0.37$ ) were not. In contrast, all three proxies were significantly related to the mean temperature during the month prior to the respective phenology: OAB was significantly related to mean March air temperature (slope: $-4.2 \pm 1.3 \mathrm{~d} /{ }^{\circ} \mathrm{C}, t=-3.1, P<0.01$ ), TDM to the mean May temperature (slope: $-4.3 \pm 0.9 \mathrm{~d} /{ }^{\circ} \mathrm{C}, t=-4.5$, $P<0.001)$, and TWH to the mean November air temperature (slope: $0.6 \pm 0.2 \mathrm{~d} /{ }^{\circ} \mathrm{C}, t=2.5, P<0.02$ ). The air temperature in these three months advanced $0.03^{\circ} \pm 0.05^{\circ} \mathrm{C}$ (March, $\left.t=0.6, P=0.55\right), 0.1^{\circ} \pm 0.04^{\circ} \mathrm{C}$ (May, $t=2.8, P<0.01$ ), and $0.04^{\circ} \pm 0.02^{\circ} \mathrm{C}$ (November, $t=1.8, P=0.08$ ). However, as the standard errors of these slopes overlap, the warming rates for these three months did not differ significantly.

Seasonally constant warming is predicted to advance TDM $5.5 \mathrm{~d} /{ }^{\circ} \mathrm{C}$ (Fig. 2b), OAB $4.1 \mathrm{~d} /{ }^{\circ} \mathrm{C}$ (Fig. 2c), and TWH $3.8 \mathrm{~d} /{ }^{\circ} \mathrm{C}$ (Fig. 2d). TWH advances with climatic warming despite a delay of TWS $\left(2.3 \mathrm{~d} /{ }^{\circ} \mathrm{C}\right.$; Fig. 3a) because the reduced duration of egg development with warming $\left(6.1 \mathrm{~d} /{ }^{\circ} \mathrm{C}\right.$; Fig. $\left.3 \mathrm{~b}\right)$ overcompensates for the delay in spawning.

Due to interannual variability of these phenologies, the time spans between phenological events varies considerably under reference conditions (zero warming in Figs. 2e-g), i.e., TDM occurred between 38 and 87 days later than $\mathrm{OAB}$, and it occurred between 88 and 148 days later than TWH. Likewise, OAB lagged between 34 and 80 days behind TWH. In comparison to this high interannual variability, the mean time spans 
between phenological events changed only marginally with warming (TDM-OAB: $-1.3 \mathrm{~d} /{ }^{\circ} \mathrm{C}$ [Fig. 2e], TDMTWH: $-1.8 \mathrm{~d} /{ }^{\circ} \mathrm{C}$ [Fig. $2 \mathrm{f}$ ], OAB-TWH: $-0.5 \mathrm{~d} /{ }^{\circ} \mathrm{C}$ [Fig. $2 \mathrm{~g}]$ ). The time span between $\mathrm{OAB}$ and TDM was affected by warming via several mechanisms: Warming resulted in an earlier $\mathrm{OAB}$ resulting from an earlier reduction in winter mixing (Fig. 2c); in higher water temperature at algal onset $\left(0.75^{\circ} \mathrm{C} /{ }^{\circ} \mathrm{C}\right.$; Fig. 3c); and in reduced average net heat influx during the period from $\mathrm{OAB}$ to $\mathrm{TDM}\left(-3.6 \mathrm{~W} \cdot \mathrm{m}^{-2} \cdot{ }^{\circ} \mathrm{C}^{-1}\right.$; Fig. $\left.3 \mathrm{~d}\right)$ primarily because of reduced short-wave solar radiation early in the season after the forward shift of algae onset (see Appendix C: Fig. $\mathrm{Cl}$ for changes of individual heat budget components).

In the season-specific warming scenarios, the amplitudes and seasonal extents of the effects of air temperature changes on water temperatures differed with respect to the specific period in which the air temperature had been changed and also with respect to the depth within the water column (Fig. 4). Furthermore, the effects further depend on other meteorological conditions such as wind speed during a specific year. For example, during a windy year (e.g., meteorological conditions as in 1988), warming in April rather than March has the strongest influence on the temperature difference between the surface and $40 \mathrm{~m}$ depth during early spring. In the years with less wind, March warming will have the strongest effect, but the effect size differs between years, e.g., between 1989 and 1990 (Fig. 4a-c). Likewise, the effect size of April warming differs between the years employed to exemplify the consequences of seasonally heterogeneous warming for temperature dynamics in the upper $5 \mathrm{~m}$ of the water column (Fig. 4d-f). The effect of a 28 -day warming period on temperature at $10 \mathrm{~m}$ depth during fall is weak compared to the shift from baseline in the $+2^{\circ} \mathrm{C}$ scenario (Fig. $4 \mathrm{~g}-\mathrm{i}$ ). This is also true for deep-water temperatures. The greatest effect of episodic warming on winter deep-water temperatures also differs between years depending on meteorological conditions (Fig. 4j-1). Because deep-water temperatures in deep lakes are not reset to $4^{\circ} \mathrm{C}$ every winter, and hence display multiannual dynamics (Fig. 4j-1), the duration of whitefish egg development in a specific year cannot be understood without considering multi-annual water temperature dynamics.

$\mathrm{OAB}$ was strongly affected by a 28-day warming period starting at the 1st or 15th of March (Fig. 5a), whereas warming in other periods had little effect on OAB. In contrast, TDM (Fig. 5b) and TWH (Fig. 5c) were affected by several warming periods. April warming advanced TDM the most (Fig. 5b). The effect decreased with warming periods occurring either earlier or later than April. TWH was most affected by warming periods during winter mixing, i.e., from December toward February, whereas surplus warming in autumn had no strong effect. The maximum effect size of a $28-$ day warming periods was rather small for TDM (Fig.
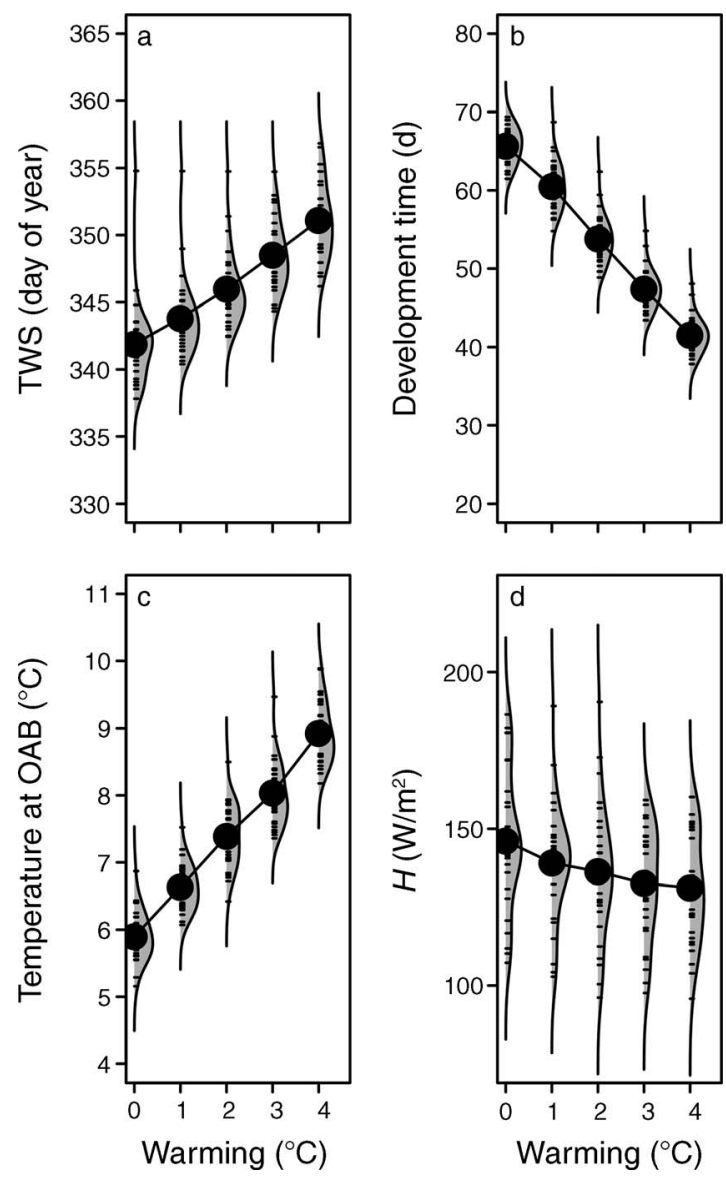

FIG. 3. Density distribution plots (shaded areas) of the effects of seasonally constant warming on (a) the timing of whitefish spawning (TWS), the (b) developmental time of whitefish eggs, (c) the temperature at the onset of the algal bloom $(\mathrm{OAB})$, and $(\mathrm{d})$ the average net heat flux $(H)$ during the period from the onset of the algal bloom to the Daphnia maximum. Black lines connect the means (black dots) of each distribution. Rugs (short black ticks) indicate individual data points.

$5 b)$ and TWH (Fig. 5c), but for OAB its magnitude was similar to that of $2^{\circ} \mathrm{C}$ year-round warming.

The effects of season-specific warming on the time span between phenological events can considerably increase, but also reverse those of constant warming depending on the months affected by the season-specific warming and the phenological events considered (Fig. $5 \mathrm{~d}-\mathrm{f})$. Although constant warming of $2^{\circ} \mathrm{C}$ decreased the time span between $\mathrm{OAB}$ and TDM, on average, by 4.2 days relative to reference simulations, the season-specific scenario with March warming led to an overall increase of 4.3 days (Fig. 5d). With respect to the time span between TWH and TDM, the effects of constant warming were only slightly modified by seasonal warming with the strongest effects from April warming scenarios, which resulted in an additional reduction of the time lag by three days compared to the $+2^{\circ} \mathrm{C}$ scenario (Fig. 5e). Strong effects of season-specific 
warming were observed for the time span between algal bloom onset and whitefish hatching: Winter warming (December-February) resulted in a slightly prolonged time span compared to the reference scenario (e.g., 1.7 days for January warming), whereas March warming resulted in a substantial shortening of this time lag (10.1 days; Fig. 5f). The reduction of the time lag in the March warming scenario is seven-fold greater than the reduction of the time lag in the year-round $+2^{\circ} \mathrm{C}$ warming scenario (1.4 days; Fig. 5f).

\section{DisCUSSION}

The interannual variability in the phenological events of algal bloom onset, Daphnia maximum, and whitefish hatching can be adequately described by temperature proxies (Appendix A: Fig A1; Peeters et al. 2007b, Wahl and Löffler 2009, Straile et al. 2012). Temperature change probably dominates phenological shifts in many ecosystems as global warming is likely the driver of the majority of the many observed changes in phenology during the last decades (Menzel et al. 2006, Thackeray et al. 2010). In addition to temperature, other factors possibly influence phenology, such as photoperiod (de Senerpont Domis et al. 2007, Körner and Basler 2010), nutrients (Thackeray et al. 2008), age structure (Wahl and Löffler 2009), and food availability or predation pressure (Wiltshire et al. 2008, Schalau et al. 2008). However, the timing of the onset of algal bloom and of the Daphnia maximum in Lake Constance are strongly related to the temperature proxies and not to other environmental drivers, e.g., oligotrophication (Peeters et al. 2007a, Straile et al. 2012). In the case of whitefish, enhanced growth rates due to eutrophication combined with the selective removal of large fish by commercial fisheries alters the age structure of the fish population, which has been shown to affect spawning time (Wahl and Löffler 2009). We therefore established our proxy for spawning time using the same time period selected by Wahl and Löffler (2009), during which this potentially confounding variable (age structure) did not show high variability, and hence, was statistically unrelated to the time of spawning (Wahl and Löffler 2009). Thus, the relationships of the phenological events to their respective proxies are unlikely to be biased by confounding environmental variation.

In this study we investigated the sensitivity of phenology to increasing air temperature, and we demonstrate that overall warming leads to a synchronous shift of three trophic levels, whereas warming that is season-specific potentially leads to a mismatch of feeding interactions. Significant changes in biotic and abiotic factors, including meteorological factors other than air temperature, may lead to shifts in phenology in addition to the consequences of changing air temperature. However, as temperature change is likely the most important driver of recent phenological shifts, our focus in this study was to provide a thorough understanding of the influence of hydrodynamically mediated seasonally constant vs. seasonally heterogeneous temperate increase on phenological change.

The relationships between air temperature and phenological proxies determined from long-term data, i.e., utilizing interannual differences in phenological proxies, are consistent with the model results for climate change scenarios for OAB and TDM, but not for of TWH. OAB and TDM advanced rather synchronously during this time period, and both were related to monthly air temperature variability with similar slopes. In contrast, TWH did not advance during the 1979-2007 period and was related to monthly air temperature variability with a slope smaller than that of $\mathrm{OAB}$ and TDM.

The discrepancy between the model results and the statistical analysis of the data with respect to the air temperature dependency of TWH is likely due to the substantial shortening of egg developmental time that occurred in the warming simulations, but not in the period 1979-2007. Such a reduction in egg developmental time will result in a considerable advance of TWH. Due to the large volume of water in a deep lake such as Lake Constance, deep-water temperatures respond to air temperature on a time scale of several years, i.e., one year of $+2^{\circ} \mathrm{C}$ is not sufficient to warm up the hypolimnion of the lake to equilibrium conditions of a permanent $+2^{\circ} \mathrm{C}$ increase (Straile et al. 2010). The deepwater temperature during 1979-2007 never reached the levels of $\mathrm{a}+2^{\circ} \mathrm{C}$ world; not even after an extremely warm winter (Straile et al. 2010). Consequently, the developmental time of whitefish eggs will be much more strongly reduced under warming conditions compared to the current conditions. This, in turn, will result in a stronger advance of $\mathrm{TWH}$ per ${ }^{\circ} \mathrm{C}$ during warming simulations compared to the advance of $\mathrm{TWH}$ per ${ }^{\circ} \mathrm{C}$ based on interannual air temperature variability during 19792007.

Furthermore, analysis of the relationships of the proxies to air temperature shows that it is not the annual mean air temperature that matters as it was not related to OAB and TWH. Only in the case of TDM was a significant relationship with annual mean air temperature observed, but the slope (days/ ${ }^{\circ} \mathrm{C}$ ) of this relationship was much steeper than the slope obtained for May air temperature or in the simulations with constant warming. In contrast, the air temperature of specific months was tightly connected to OAB, TMD, and TWH, suggesting that the phenological events and their potential mismatch are specifically sensitive to seasonspecific warming.

The synchrony of phenological change with seasonally constant warming is not merely a trivial consequence of synchronous shifts of isotherms with warming, but instead it results from complex and opposing physical and biological processes. The synchronous change of $\mathrm{OAB}$ and TDM results at least partially from the opposing effects of higher water 

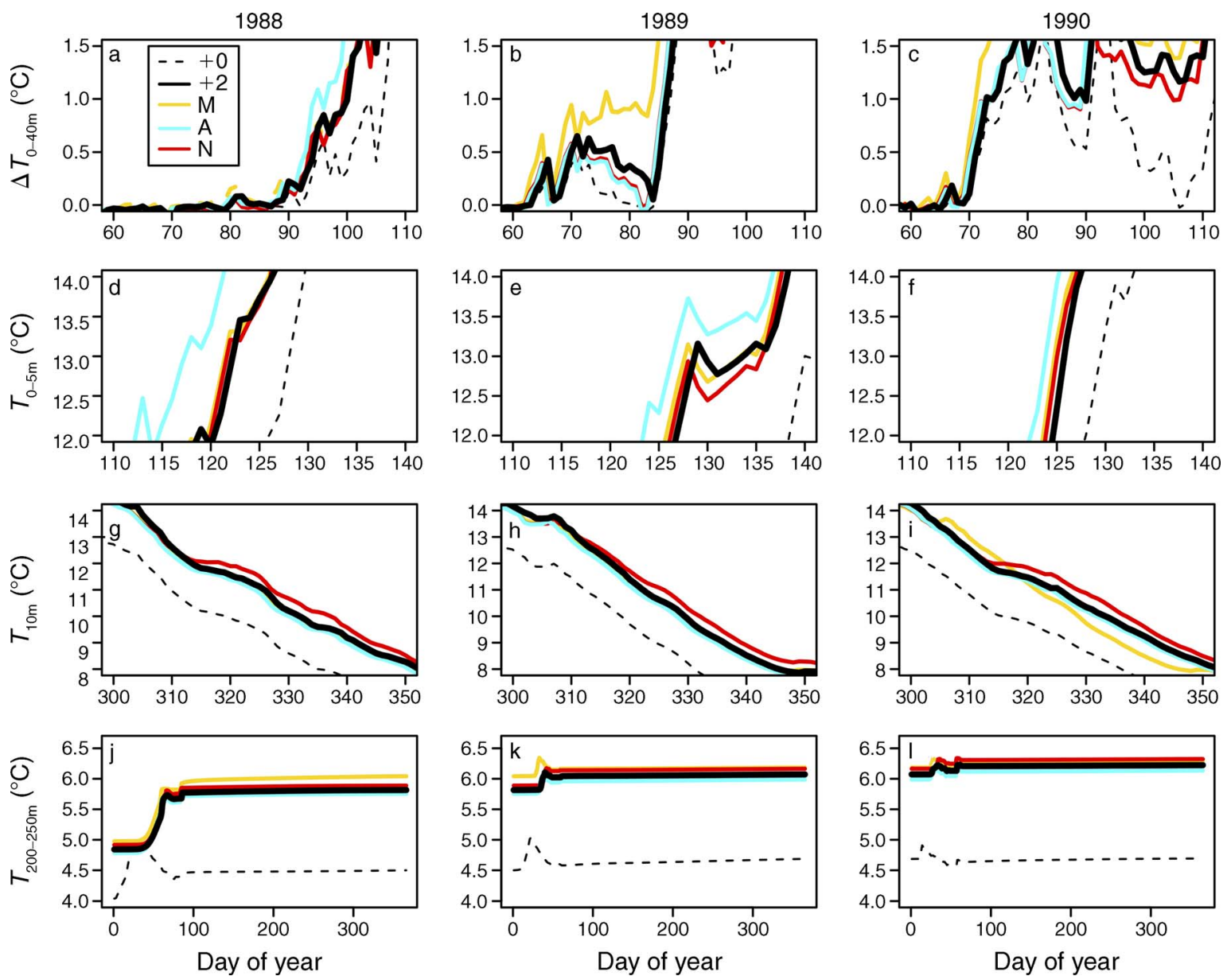

FIG. 4. Predicted consequences of season-specific warming for water temperature dynamics in three years with contrasting meteorology. Model results are shown for the years 1988, 1989, and 1990. (a-c) Temperature differences between the surface and 40 $\mathrm{m}$ depth $\left(\Delta T_{0-40 \mathrm{~m}}\right)$ in late winter/early spring, (d-f) the average temperatures in the upper $5 \mathrm{~m}$ of the water column $\left(T_{0-5 \mathrm{~m}}\right)$ during spring, (g-i) the temperature at $10 \mathrm{~m}$ water depth $\left(T_{10 \mathrm{~m}}\right)$ during November, $(\mathrm{j}-1)$ the average temperatures from 200 to $250 \mathrm{~m}$ depth $\left(T_{200-250 \mathrm{~m}}\right)$ throughout the year under reference conditions $(+0)$, constant seasonal warming of $2^{\circ} \mathrm{C}(+2)$, and season-specific warming scenarios with 28-day warming periods of $4^{\circ} \mathrm{C}$ in air temperature starting on the 1st of March (M), April (A), and November $(\mathrm{N})$ at an annual average warming of $2^{\circ} \mathrm{C}$.

temperature during winter mixing and a reduced warming rate immediately after the onset of stratification in a warmer climate. The latter is a consequence of the seasonal advance of the onset of stratification and the seasonal change in solar radiation with lower values earlier in the season.

Thus, despite the elevated water temperatures at the onset of stratification, the time span between OAM and TDM is predicted to remain unchanged in a warmer climate in deep stratifying lakes. Additional research is needed to clarify whether our results are also valid in shallower lakes and in lakes with annual ice cover. Although the timing of the Daphnia maximum in these lakes follows the same isotherm relationship as in deep lakes (Straile et al. 2012), the onset of phytoplankton growth in shallower systems usually depends not on the onset of stratification, but on the timing of ice-off (Weyhenmeyer et al. 1999) or other factors. While the timing of ice-off also advances with warming (Magnuson et al. 2000), it is not clear whether the advance of ice-off will also be synchronous with the advance of water temperature isotherms such as the $13^{\circ} \mathrm{C}$ isotherm in the upper $5 \mathrm{~m}$ of the water column.

Synchrony between TWH and the other phenological events considered in this study (OAB and TDM) results from the opposing effect of warming on TWS and egg developmental time on TWH. A large mismatch between whitefish and their resources might be expected because spawning in Lake Constance is substantially delayed with warming. A delay in spawning with warmer temperatures has been reported also for other salmonids in studies analyzing latitudinal variability in spawning (Heggberget 1988, Pankhurst and Munday 2011). In this context, delayed spawning with higher temperatures has been suggested to be adaptive, allowing egg hatching at an optimal time for the survival 

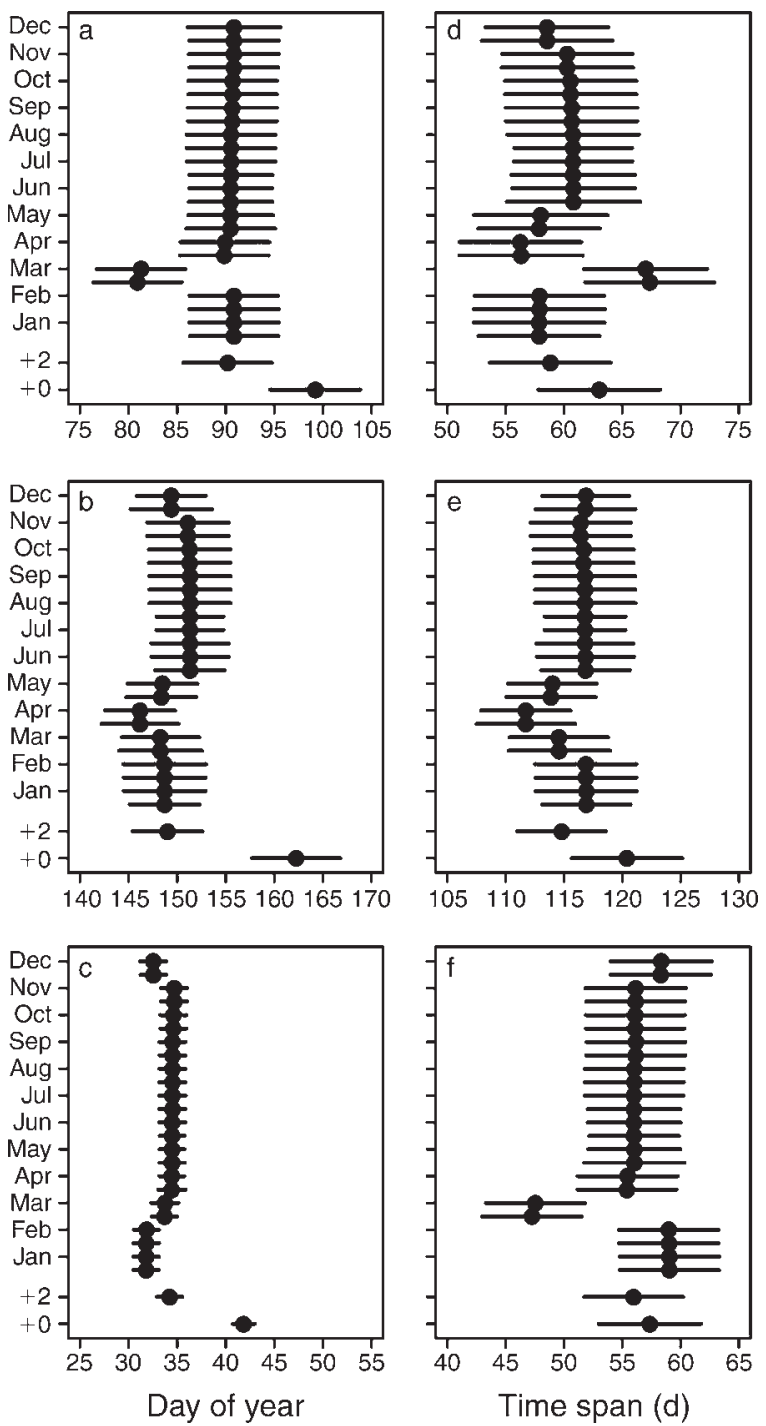

FIG. 5. Effects of seasonally constant and season-specific warming scenarios on phenologies (mean $\pm 2 \mathrm{SE}$ ) of the (a) onset of the algal bloom, (b) Daphnia maximum, (c) whitefish hatching, and time spans between phenologies of the (d) onset of the algal bloom and Daphnia maximum, (e) whitefish hatching and Daphnia maximum, and (f) onset of the algal bloom and whitefish hatching in comparison to reference conditions. Warming scenarios include: no warming $(+0)$, seasonally constant warming of $2^{\circ} \mathrm{C}(+2)$, and 28-day long warming periods of $4^{\circ} \mathrm{C}$ in air temperature starting at the $1 \mathrm{st}$ and 15th day of each month, respectively, in scenarios within annual average warming rates of $+2^{\circ} \mathrm{C}$.

of fry (Heggberget 1988, Pankhurst and Munday 2011). In contrast, delayed spawning with higher temperature due to climate warming has been considered to be maladaptive (Warren et al. 2012), as this might desynchronize larval fish from their plankton food, which likely advances with warming. Our results suggest that delayed spawning does not necessarily result in desynchronization of fish larvae from their resources because the egg developmental time may be substantially reduced in a warmer climate. In contrast, because of shorter egg developmental times, delayed spawning might actually prevent the advancement of larval hatching from exceeding the advancement of $\mathrm{OAB}$ and TDM.

Whereas phenological advancement with seasonally constant warming will not differ strongly between three trophic levels suggesting a low risk of trophic mismatch even in the absence of evolutionary adaptation, seasonspecific warming may cause changes in the time span between phenological events of interacting populations and thus potentially disrupt food web interactions. The differential impact of seasonally constant vs. seasonspecific warming has strong implications for climateimpact research beyond the food webs of aquatic systems:

1) There is a need for a critical re-evaluation of previously reported mismatches and food web disruptions due to global warming to analyze to what extent they were the result of season-specific warming. For example, one of the best known examples of the disruption of trophic interactions due to climate warming from planktonic food webs, the warming-induced mismatch between water fleas and algae in Lake Washington, has recently been suggested to result from season-specific warming (Straile et al. 2012). Likewise, the synchronous advance of $\mathrm{OAB}$ and TDM in Lake Constance during 1979-2007 may be expected as both showed similar advances per ${ }^{\circ} \mathrm{C}$ and warming trends for the months March and May did not differ significantly. In terrestrial ecosystems, differences in phenological responses between trees and their butterfly pollinators in Japan were attributed to seasonal heterogeneity in warming (Doi et al. 2008). Furthermore, spatial variability in the occurrence of a trophic mismatch between Great Tits (Parus major) and their prey has been at least partially attributed to spatial variability in season-specific warming patterns (Visser et al. 2003). Re-evaluation of reported mismatches and heterogeneities in phenological responses between species with respect to the seasonality of warming will provide a better understanding of warming effects on phenology and will also provide new insights into the role of phenology in trophic interactions.

2) To predict the threat of food web disruptions, the seasonal isotherms most crucial to the phenological events of interacting species need to be identified. If there is little difference between critical isotherms, then the phenological events of the interacting species will likely be shifted synchronously by warming (Ovaskainen et al. 2013). However, especially for interactions in which long-lived organisms are involved, the crucial isotherms may differ considerably, suggesting a higher risk of food web disruptions due to season-specific warming. 

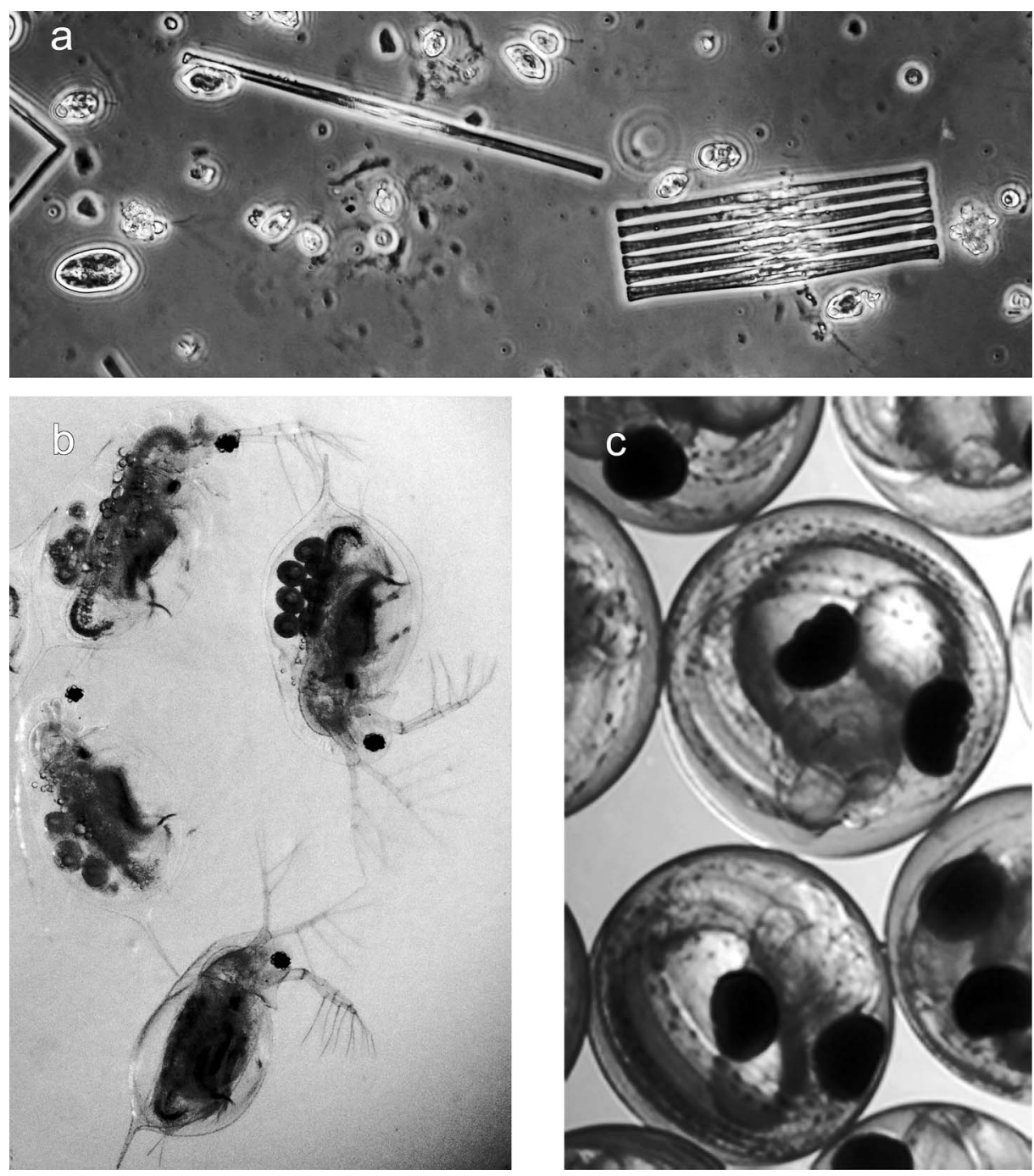

Plate 1. Organisms of which phenologies have been analyzed in this study: (a) typical members of the spring phytoplankton community in Lake Constance, Germany (diatoms and cryptophytes); (b) water fleas (Daphnia galaeata), and (c) whitefish embryos shortly before hatching. Photo credits: (a) and (b) by D. Straile; (c) by Reiner Eckmann.

3) The degree and even direction of asynchronous phenological change with season-specific warming depends on the specifics of the seasonal heterogeneity, i.e., whether for example March warming exceeds April warming, or vice versa. Hence, predicting trophic mismatches between interacting species requires reliable warming predictions on a seasonal or even sub-seasonal scale.

4) Experimental studies analyzing the consequences of phenological changes for food webs have usually been performed using constant-warming scenarios or differential warming in summer vs. winter, but not with within-season heterogeneity of warming (Nicolle et al. 2012, Sommer et al. 2012, Stewart et al. 2013). These studies have often reported no strong evidence for trophic mismatch with warm- ing, which is in line with the constant-warming scenarios, but contrary to the de-synchronization of trophic interactions observed in numerous ecosystems during the last decades (Parmesan and Yohe 2003, Thackeray et al. 2010, Poloczanska et al. 2013) and the season-specific warming scenarios of this study. This suggests that there is a need for experimental studies testing the relevance of seasonspecific warming for trophic interactions. A first step in this direction are mesocosm experiments manipulating the effects of warming and light availability independently (Berger et al. 2007, 2014, Winder et al. 2012). These studies have failed to detect a strong mismatch between algae and herbivores. However, as the effect of light reduction in these experiments was a reduction in biomass and 
growth rates of algae after bloom onset and not a shift in bloom onset, manipulating warming and light availability independently is not perfectly analogous to experimentally manipulating seasonspecific warming.

Climate change is likely to change ecosystems in a multitude of ways because of changes in the metabolic rates of organisms at higher temperatures (e.g., O'Connor et al. 2009), altered frequency and duration of seasonally adverse conditions (e.g., McCaffery and Maxell 2010), and local species invasions and/or extinctions (e.g., Thomas et al. 2004). Mismatching due to heterogeneity in phenological advancement is an additional process possibly changing the structure of food webs. In our study, we suggest that with seasonally constant warming, heterogeneity in phenological advancement is not a major concern. Clearly, this finding does not exclude the possibility that seasonally constant warming will result in ecosystem change via other mechanisms, nor the reversal of cause and effect, that a change in overall food web structure due to warming might alter species phenology. Furthermore, we show that in contrast to seasonally constant warming, seasonally heterogeneous warming has greater potential to result in food web disruptions, and therefore must be considered when predicting the response of ecosystems to climate warming.

\section{ACKNOWLEDGMENTS}

Data were provided by the German National Meteorological Service (meteorological data), the Institute for Lake Research, Langenargen (deep-water temperatures), and Roland Rösch and Bernd Wahl (whitefish spawning dates). We thank Sebastian Diehl and one anonymous reviewer for insightful comments that improved the clarity of the manuscript and Joel Trexler for improving the English. Financial support was given by the University of Konstanz and the Deutsche Forschungsgemeinschaft (project PE 701/2-1 within the AQUASHIFT program [SPP 1162] and project STR 499/6-1).

\section{Literature Cited}

Adrian, R., S. Wilhelm, and D. Gerten. 2006. Life-history traits of lake plankton species may govern their phenological response to climate warming. Global Change Biology 12: 652-661.

Berger, S., S. Diehl, H. Stibor, P. Sebastian, and A. Scherz. 2014. Separating effects of climatic drivers and biotic feedbacks on seasonal plankton dynamics: no sign of trophic mismatch. Freshwater Biology 59:2204-2220.

Berger, S. A., S. Diehl, H. Stibor, G. Trommer, M. Ruhenstroth, A. Wild, A. Weigert, C. G. Jager, and M. Striebel. 2007. Water temperature and mixing depth affect timing and magnitude of events during spring succession of the plankton. Oecologia 150:643-654.

Blois, J. L., P. L. Zarnetzke, M. C. Fitzpatrick, and S. Finnegan. 2013. Climate change and the past, present, and future of biotic interactions. Science 341:499-504.

Both, C., M. van Asch, R. G. Bijlsma, A. B. van den Burg, and M. E. Visser. 2009. Climate change and unequal phenological changes across four trophic levels: constraints or adaptations? Journal of Animal Ecology 78:73-83.

Burakowski, E. A., C. P. Wake, B. Braswell, and D. P. Brown. 2008. Trends in wintertime climate in the northeastern
United States: 1965-2005. Journal of Geophysical Research 113:D20114

Burrows, M. T., et al. 2011. The pace of shifting climate in marine and terrestrial ecosystems. Science 334:652-655.

Cushing, D. H. 1990. Plankton production and year-class strength in fish populations: an update of the match/ mismatch hypotheses. Advances in Marine Biology 26:249293.

de Senerpont Domis, L. N., W. M. Mooij, S. Hülsmann, E. H. van Nes, and M. Scheffer. 2007. Can overwintering versus diapausing strategy in Daphnia determine match-mismatch events in zooplankton-algae interactions? Oecologia 150: 682-698.

Doi, H., O. Gordo, and I. Katano. 2008. Heterogeneous intraannual climatic changes drive different phenological responses at two trophic levels. Climate Research 36:181-190.

Eckmann, R. 1987. A comparative study on the temperature dependence of embryogenesis in three coregonids (Coregonus spp.) from Lake Constance. Schweizerische Zeitschrift für Hydrologie 49:353-362.

George, D. G. 2012. The effect of nutrient enrichment and changes in the weather on the abundance of Daphnia in Esthwaite Water, Cumbria. Freshwater Biology 57:360372.

Goudsmit, G. H., H. Burchard, F. Peeters, and A. Wuest. 2002. Application of $\mathrm{k}$-epsilon turbulence models to enclosed basins: The role of internal seiches. Journal of Geophysical Research-Oceans 107:C12, 3230.

Heggberget, T. G. 1988. Timing of spawning in Norwegian Atlantic salmon (Salmo salar). Canadian Journal of Fisheries and Aquatic Sciences 45:845-849.

Huisman, J., P. van Oostveen, and F. J. Weissing. 1999. Critical depth and critical turbulence: Two different mechanisms for the development of phytoplankton blooms. Limnology and Oceanography 44:1781-1787.

IPCC [Intergovernmental Panel on Climate Change]. 2013. Climate change 2013: the physical science basis. IPCC, Geneva, Switzerland.

Kampstra, P. 2008. Beanplot: a boxplot alternative for visual comparison of distributions. Journal of Statistical Software 28:1-9.

Körner, C., and D. Basler. 2010. Phenology under global warming. Science 327:1461-1462.

Magnuson, J. J., et al. 2000. Historical trends in lake and river ice cover in the Northern Hemisphere. Science 289:17431746.

McCaffery, R. M., and B. A. Maxell. 2010. Decreased winter severity increases viability of a montane frog population. Proceedings of the National Academy of Sciences USA 107: 8644-9649.

Menzel, A., et al. 2006. European phenological response to climate change matches the warming pattern. Global Change Biology 12:1969-1976.

Nicolle, A., P. Hallgren, J. von Einem, E. S. Kritzberg, W. Granéli, A. Persson, C. Brönmark, and L.-A. Hansson. 2012. Predicted warming and browning affect timing and magnitude of plankton phenological events in lakes: a mesocosm study. Freshwater Biology 57:684-695.

O'Connor, M. I., M. F. Piehler, D. M. Leech, A. Anton, and J. F. Bruno. 2009. Warming and resource availability shift food web structure and metabolism. PLoS Biology 7: e1000178.

Ohlberger, J., S. J. Thackeray, I. J. Winfield, S. C. Maberly, and L. A. Vollestad. 2014. When phenology matters: age-size truncation alters population response to trophic mismatch. Proceedings of the Royal Society B 281:20140938.

Ovaskainen, O., S. Skorokhodova, M. Yakovleva, A. Sukhov, A. Kutenkov, N. Kutenkova, A. Shcherbakov, E. Meyke, and M. D. M. Delgado. 2013. Community-level phenological response to climate change. Proceedings of the National Academy of Sciences USA 110:13434-13439. 
Pankhurst, N. W., and P. L. Munday. 2011. Effects of climate change on fish reproduction and early life history stages. Marine and Freshwater Research 62:1015.

Parmesan, C., and G. Yohe. 2003. A globally coherent fingerprint of climate change impacts across natural systems. Nature 421:37-42.

Peeters, F., D. Straile, A. Lorke, and D. M. Livingstone. $2007 a$. Earlier onset of the spring phytoplankton bloom in lakes of the temperate zone in a warmer climate. Global Change Biology 13:1898-1909.

Peeters, F., D. Straile, A. Lorke, and D. Ollinger. $2007 b$. Turbulent mixing and phytoplankton spring bloom development in a deep lake. Limnology and Oceanography 52:286298.

Perroud, M., S. Goyette, A. Martynov, M. Beniston, and O. Anneville. 2009. Simulation of multiannual thermal profiles in deep Lake Geneva: A comparison of one-dimensional lake models. Limnology and Oceanography 54:1574-1594.

Poloczanska, E. S., et al. 2013. Global imprint of climate change on marine life. Nature Climate Change 3:919-925.

R Development Core Team. 2009. R: a language and environment for statistical computing. R Foundation for Statistical Computing, Vienna, Austria. http://www. $\mathrm{R}$-project.org

Räisänen, J., U. Hansson, A. Ullerstig, R. Döscher, L. P. Graham, C. Jones, H. E. M. Meier, P. Samuelsson, and U. Willén. 2004. European climate in the late twenty-first century: regional simulations with two driving global models and two forcing scenarios. Climate Dynamics 22:13-31.

Rebetez, M., and M. Reinhard. 2007. Monthly air temperature trends in Switzerland 1901-2000 and 1975-2004. Theoretical and Applied Climatology 91:27-34.

Schalau, K., K. Rinke, D. Straile, and F. Peeters. 2008. Temperature is the key factor explaining interannual variability of Daphnia development in spring: a modelling study. Oecologia 157:531-43.

Schaper, S. V., A. Dawson, P. J. Sharp, P. Gienapp, S. P. Caro, and M. E. Visser. 2012. Increasing temperature, not mean temperature, is a cue for avian timing of reproduction. American Naturalist 179:E55-69.

Seebens, H., U. Einsle, and D. Straile. 2009. Copepod life cycle adaptations and success in response to phytoplankton spring bloom phenology. Global Change Biology 15:1394-1404.

Sommer, U., R. Adrian, B. Bauer, and M. Winder. 2012. The response of temperate aquatic ecosystems to global warming: novel insights from a multidisciplinary project. Marine Biology 159:2367-2377.

Stewart, R. I. A., et al. 2013. Mesocosm experiments as a tool for ecological climate-change research. Advances in Ecological Research 48:69-179.

Straile, D., R. Adrian, and D. E. Schindler. 2012. Uniform temperature dependency in the phenology of a keystone herbivore in lakes of the Northern Hemisphere. PLoS ONE 7:e45497.
Straile, D., R. Eckmann, T. Jüngling, G. Thomas, and H. Löffler. 2007. Influence of climate variability on whitefish (Coregonus lavaretus) year-class strength in a deep, warm monomictic lake. Oecologia 151:521-529.

Straile, D., O. Kerimoglu, F. Peeters, M. C. Jochimsen, R. Kümmerlin, K. Rinke, and K. O. Rothhaupt. 2010. Effects of a half a millennium winter on a deep lake: a shape of things to come? Global Change Biology 16:2844-2856.

Thackeray, S. J., I. D. Jones, and S. C. Maberly. 2008. Longterm change in the phenology of spring phytoplankton: species-specific responses to nutrient enrichment and climatic change. Journal of Ecology 96:523-535.

Thackeray, S. J., et al. 2010. Trophic level asynchrony in rates of phenological change for marine, freshwater and terrestrial environments. Global Change Biology 16:3304-3313.

Thomas, C. D., et al. 2004. Extinction risk from climate change. Nature 427:145-148.

Visser, M. E., et al. 2003. Variable responses to large-scale climate change in European Parus populations. Proceedings of the Royal Society B 270:367-72.

Visser, M. E., and C. Both. 2005. Shifts in phenology due to global climate change: the need for a yardstick. Proceedings of the Royal Society B 272:2561-2569.

Wahl, B., and H. Löffler. 2009. Influences on the natural reproduction of whitefish (Coregonus lavaretus) in Lake Constance. Canadian Journal of Fisheries and Aquatic Sciences 66:547-556.

Warren, D. R., J. M. Robinson, D. C. Josephson, D. R. Sheldon, and C. E. Kraft. 2012. Elevated summer temperatures delay spawning and reduce redd construction for resident brook trout (Salvelinus fontinalis). Global Change Biology 18:1804-1811.

Warton, D. I., R. A. Duursma, D. S. Falster, and S. Taskinen. 2012. smatr 3: an R package for estimation and inference about allometric lines. Methods in Ecology and Evolution 3: 257-259.

Weyhenmeyer, G. A., T. Blenckner, and K. Pettersson. 1999. Changes of the plankton spring outburst related to the North Atlantic Oscillation. Limnology and Oceanography 44:17881792.

Wiltshire, K. H., A. M. Malzahn, K. Wirtz, W. Greve, S. Janisch, P. Mangelsdorf, B. F. J. Manly, and M. Boersma. 2008. Resilience of North Sea phytoplankton spring bloom dynamics: An analysis of long-term data at Helgoland Roads. Limnology and Oceanography 53:1294-1302.

Winder, M., S. a. Berger, A. Lewandowska, N. Aberle, K. Lengfellner, U. Sommer, and S. Diehl. 2012. Spring phenological responses of marine and freshwater plankton to changing temperature and light conditions. Marine Biology 159:2491-2501.

Winder, M., and D. E. Schindler. 2004. Climate change uncouples trophic interactions in an aquatic ecosystem. Ecology 85:2100-2106.

\section{Supplemental Material}

\section{Ecological Archives}

Appendices A-C are available online: http://dx.doi.org/10.1890/14-0839.1.sm 
Dietmar Straile, Onur Kerimoglu, and Frank Peeters. 2015. Trophic mismatch requires seasonal heterogeneity of warming. Ecology 96:2794-2805. http://dx.doi.org/10.1890/14-0839.1

\section{Appendix A. Relationship between whitefish spawning phenology and water temperature} isotherms.
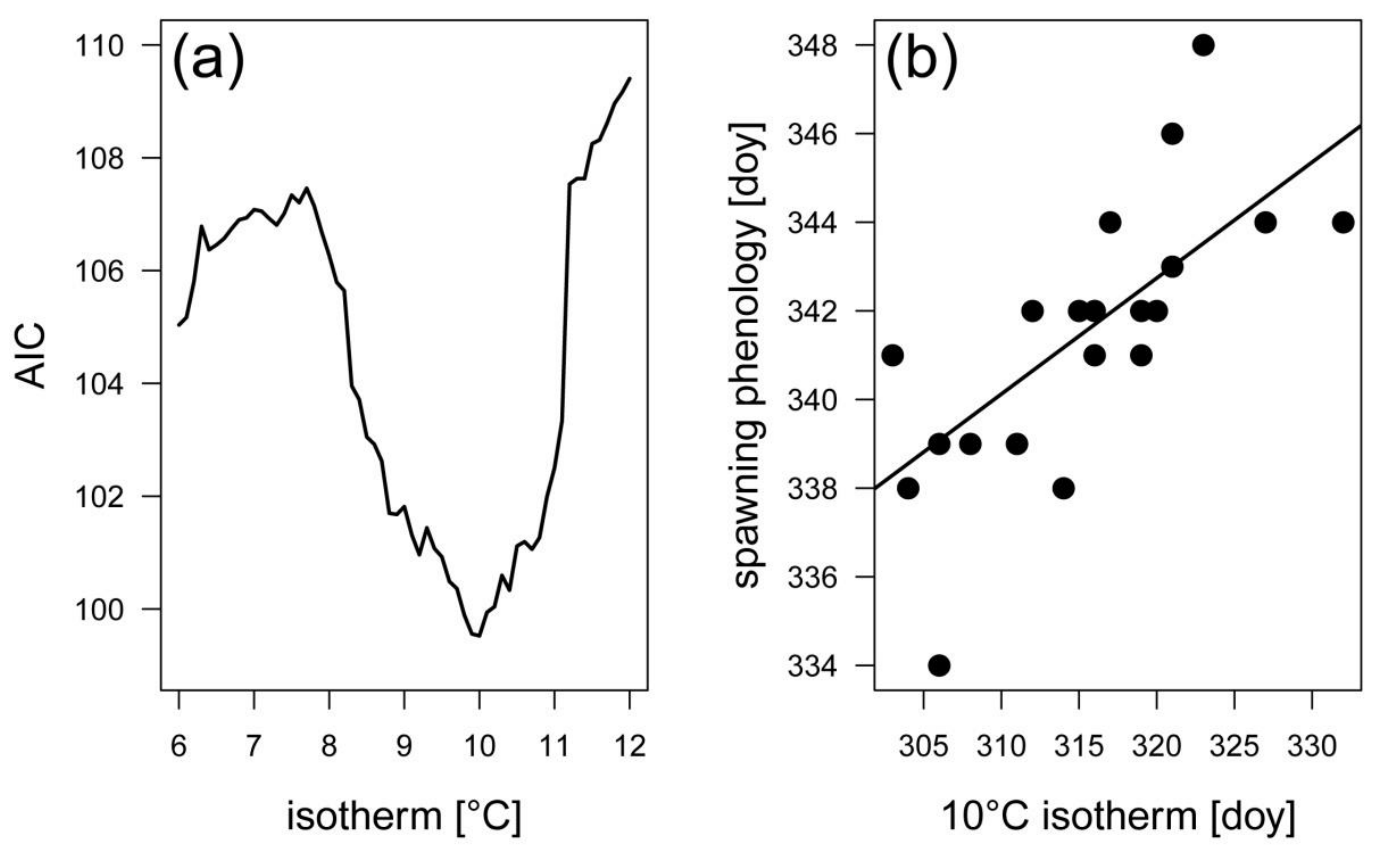

Fig. A1. Exploratory analysis to identify the seasonal isotherm best suited to predict whitefish hatching. a) AIC of linear models with auto-correlated errors to predict whitefish hatching with different temperature isotherms. Models with smaller AIC are considered to be better. b) Relationship between spawning phenology and the $10^{\circ} \mathrm{C}$ isotherm. The timing of whitefish spawning can be predicted as: Timing of whitefish spawning [doy] $=259+0.26 *$ Timing $10^{\circ} \mathrm{C}$ isotherm [doy] $(\mathrm{n}=21, \mathrm{p}<0.0005)$. 
Dietmar Straile, Onur Kerimoglu, and Frank Peeters. 2015. Trophic mismatch requires seasonal heterogeneity of warming. Ecology 96:2794-2805. http://dx.doi.org/10.1890/14-0839.1

\section{Appendix B. Additional methods: Calculation of heat fluxes.}

As in Goudsmit et al. (2002) the heat budget considers heat fluxes due to short wave radiation $H_{S}$, long wave radiation from the atmosphere $H_{A}$, long wave radiation from the water surface $H_{W}$, evaporation $H_{E}$ and conduction $H_{C}$. The net heat flux $\mathrm{H}$ is calculated as

$$
H=H_{S}+H_{A}+H_{W}+H_{E}+H_{C}
$$

The heat fluxes are calculated from meteorological data and surface water temperatures obtained from the lake model using the bulk formulae of Livingstone and Imboden (1989) in case of $H_{W}, H_{E}$ and $H_{C}$ (see Goudsmit et al. 2002) and Izomon et al. (2003) in case of $H_{A}$. Data on short wave radiation $S$ were available from the meteorological station and $H_{S}$ was calculated by estimating reflection of short wave radiation according to Ollinger (1999) assuming a smooth water surface.

\section{Meteorological and lake data required for the calculation of the heat fluxes}

$T_{a}:$ air temperature $\left[{ }^{\circ} \mathrm{C}\right]$

$T_{w}$ : surface water temperature $\left[{ }^{\circ} \mathrm{C}\right]$

$h$ : relative humidity [-]

$S:$ solar radiation $\left[\mathrm{Wm}^{-2}\right]$

$C l$ : cloud cover [-]

$p_{\text {air }}$ : air pressure $[\mathrm{hPa}]$

$u_{10}$ : wind speed $10 \mathrm{~m}$ above ground $\left[\mathrm{m} \mathrm{s}^{-1}\right]$ 
Vapor pressure of water in the atmosphere $V P_{a}$ and immediately at the lake surface $V P_{w}$ were calculated after Gill (1982):

$$
\begin{aligned}
& V P_{a}=h \cdot\left(1.0+10^{-6} \cdot p_{\text {air }} \cdot\left(4.5+6 \cdot 10^{-4} \cdot T_{a} \cdot T_{a}\right)\right) \cdot 10^{(0.7859+0.03477 \cdot T a) /(1+0.00412 \cdot T a)} \quad[\mathrm{hPa}] \\
& V P_{w}=\left(1.0+10^{-6} \cdot p_{\text {air }} \cdot\left(4.5+6 \cdot 10^{-4} \cdot T_{w} \cdot T_{w}\right)\right) \cdot 10^{(0.7859+0.03477 \cdot T w) /(1+0.00412 \cdot T w)} \quad[\mathrm{hPa}]
\end{aligned}
$$

\section{Bulk formulae for the heat fluxes}

All heat fluxes are defined positive for heat fluxes directed from the atmosphere to the lake.

Heat flux due to long wave radiation from the atmosphere based on Iziomon et al. (2003)

$$
\begin{aligned}
& H_{A}=p_{1} \cdot\left(1-r_{a}\right) \cdot R_{A} \\
& R_{A}=5.67 \mathrm{e}-8 \cdot\left(273.15+T_{a}\right)^{4}(1+0.0035 \cdot \mathrm{Cl} \cdot \mathrm{Cl} \cdot 64) \cdot\left(1-0.35 \cdot \mathrm{e}^{(-10 \cdot \mathrm{VPal}(\mathrm{Ta}+273.15))}\right) \\
& \text { long wave radiation from the atmosphere (Iziomon et al. 2003) } \\
& r_{a}=0.03 \quad \text { ratio of reflected long-wave irradiance } \\
& p_{1}=0.99527 \quad \text { calibration parameter (see also Goudsmit et al. 2002) }
\end{aligned}
$$

Heat flux due to short wave irradiance (Ollinger 1999)

$$
\begin{array}{cc}
H_{S}=\left(1-r_{d i r}\right) \cdot S_{\text {dir }}+\left(1-r_{\text {diff }}\right) \cdot S_{\text {diff }} & \\
S_{d i r}=(0.8-0.8 \mathrm{Cl}) \cdot S & \text { direct solar radiation } \\
S_{\text {diff }}=(0.2+0.8 \mathrm{Cl}) \cdot S & \text { diffuse short wave radiation }
\end{array}
$$




$$
\begin{array}{ll}
r_{\text {dir }:} & \text { fraction of reflected direct solar radiation, which is } \\
& \text { calculated from the Fresnel equations and an } 1.33 \text { as index } \\
& \text { of refraction. } r_{\text {dir }} \text { depends on the angle of the incident light } \\
& \text { and therefore varies with time. } \\
r_{\text {diff }}=\left(C l \cdot 0.05+(1-C l) \cdot r_{\text {diff,c }}\right) & \text { fraction of reflection diffusive } \\
& \text { short wave radiation } \\
& \text { fraction of reflected diffusive short wave radiation for clear } \\
r_{\text {diff,c: }} & \text { sky conditions based on Dirmhirn (1964). } r_{\text {diff }} \text { depends on } \\
& \text { the zenith angle and therefore varies with time. }
\end{array}
$$

Heat flux due to long-wave radiation from the water surface (Livingstone and Imboden 1989)

$$
H_{W}=-0.97 \cdot 5.67 \cdot 10^{-8} \cdot\left(T_{w}+273.15\right)^{4}
$$

Heat flux due to evaporation (Latent heat flux) (Livingstone and Imboden 1989)

$$
\begin{aligned}
& H_{E}=-f_{u}^{*} \cdot\left(V P_{W}-V P_{A}\right) \text { (B.11) } \\
& f_{u}=4.4+1.82 \cdot u_{10}+0.26 \cdot\left(T_{w}-T_{a}\right) \\
& p_{2}=0.97521 \\
& \text { calibration parameter (see also Livingstone and Imboden } \\
& 1989 \text { and Goudsmit et al. 2002) } \\
& f_{u}^{*}=p_{2} \cdot f_{u}
\end{aligned}
$$$$
1989 \text { and Goudsmit et al. 2002) }
$$

Sensible heat flux (Livingstone and Imboden 1989)

$$
\begin{array}{cc}
H_{C}=-f_{u}^{*} \cdot B O \cdot\left(T_{w}-T_{a}\right) & \\
B O=0.61 & \text { Bowen constant }
\end{array}
$$




\section{References}

Drimhirn, I. 1964. Das Strahlungsfeld im Lebensraum. Akad. Verl.-G., Frankfurt am Main. $426 \mathrm{pp}$.

Gill, A. E. 1982. Atmosphere-ocean dynamics. Academic. Press.

Goudsmit, G-H., H. Burchard, F. Peeters, and A. Wüest. 2002. Application of k- $\varepsilon$ turbulence models to lakes - the role of internal seiches. Journal of Geophysical Research 107: 32303242 .

Iziomon, M.G., Mayer H., Matzarakis A. 2003. Downward atmospheric longwave irradiance under clear and cloudy skies: Measurement and parameterization. Journal of Atmospheric and Solar-Terrestrial Physics 65: 1107- 1116.

Livingstone, D. M., and D. M. Imboden. 1989. Annual heat balance and equilibrium temperature of Lake Aegeri, Switzerland. Aquatic Sciences 51: 351-369.

Ollinger, D. 1999. Modellierung von Temperatur, Turbulenz und Algenwachstum mit einem gekoppelten physikalisch-biologischen Modell. Dissertation, Ruprechts-Karls-Universität, Heidelberg, ISBN 3-933342-38-4, 200pp. 
Dietmar Straile, Onur Kerimoglu, and Frank Peeters. 2015. Trophic mismatch requires seasonal

heterogeneity of warming. Ecology 96:2794-2805. http://dx.doi.org/10.1890/14-0839.1

\section{Appendix C. Change of average heat fluxes in the time period between the algal onset and}

\section{Daphnia maximum with seasonally constant warming.}

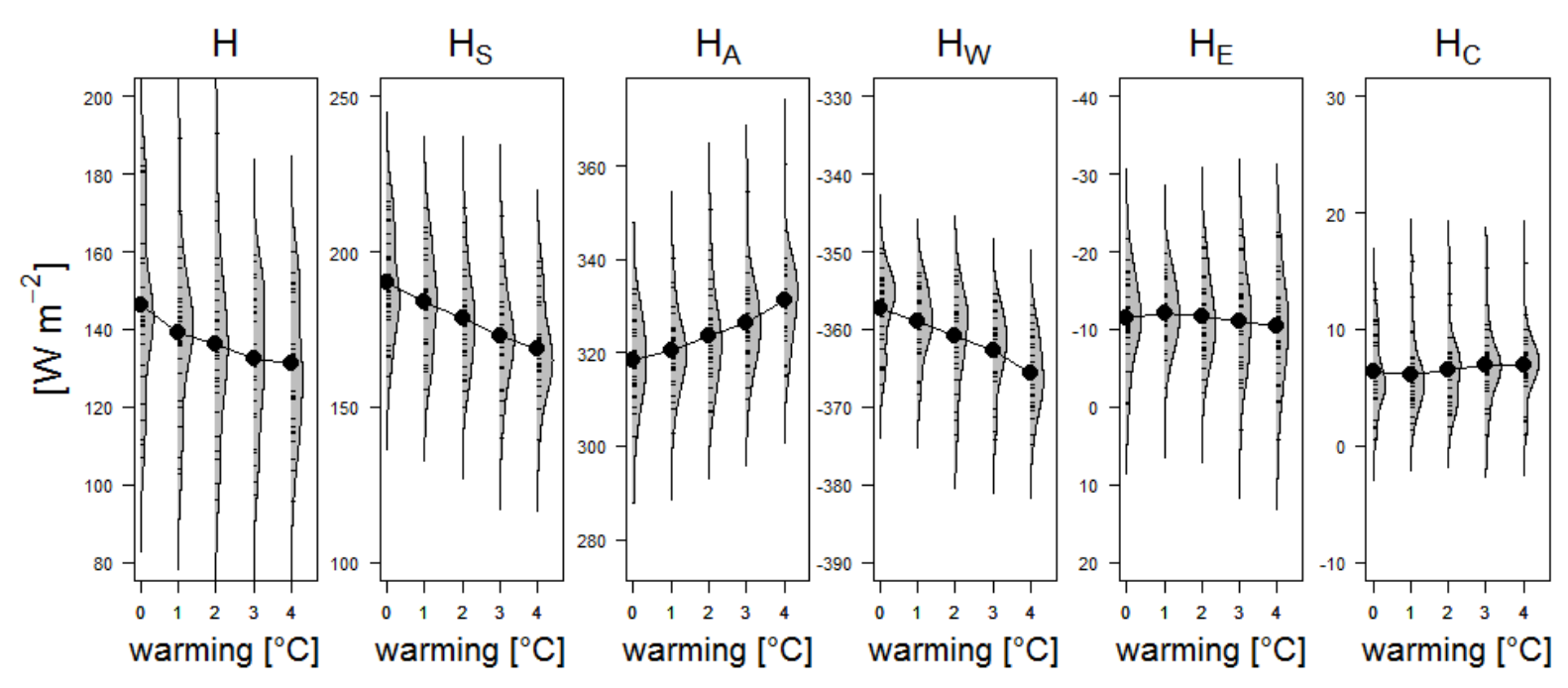

Fig. C1: Density distribution plots of the effects of seasonally constant warming on average heat fluxes in the time period between the algal onset and Daphnia maximum. Net heat flux $H$, short wave radiation $H_{S}$, long wave radiation from the atmosphere $H_{A}$, long wave radiation from the water surface $H_{W}$, heat flux due to evaporation $H_{E}$ and conduction $H_{C}$ averaged between algal onset and Daphnia maximum in the reference scenario and scenarios with seasonally constant warming of $1,2,3$, and $4^{\circ} \mathrm{C}$. Significant changes with warming occurred for $H$ (slope: $-3.6 \pm$ $1.1, \mathrm{p}<0.01$ ) $H_{S}$ (slope: $-5.3 \pm 0.9, \mathrm{p}<0.001$ ), $H_{A}$ (slope: $3.1 \pm 0.5, \mathrm{p}<0.001$ ) and $H_{W}$ (slope: $-2.0 \pm 0.3, \mathrm{p}<0.001)$, whereas $H_{E}$ and $H_{C}$ did not change significantly. Note the signs on the yaxis in the different panels: Positive heat fluxes are directed from the atmosphere to the lake, negative heat fluxes are directed from the lake to the atmosphere. Lines connect the means (black dots) of each distribution. Rugs indicate individual data points. 